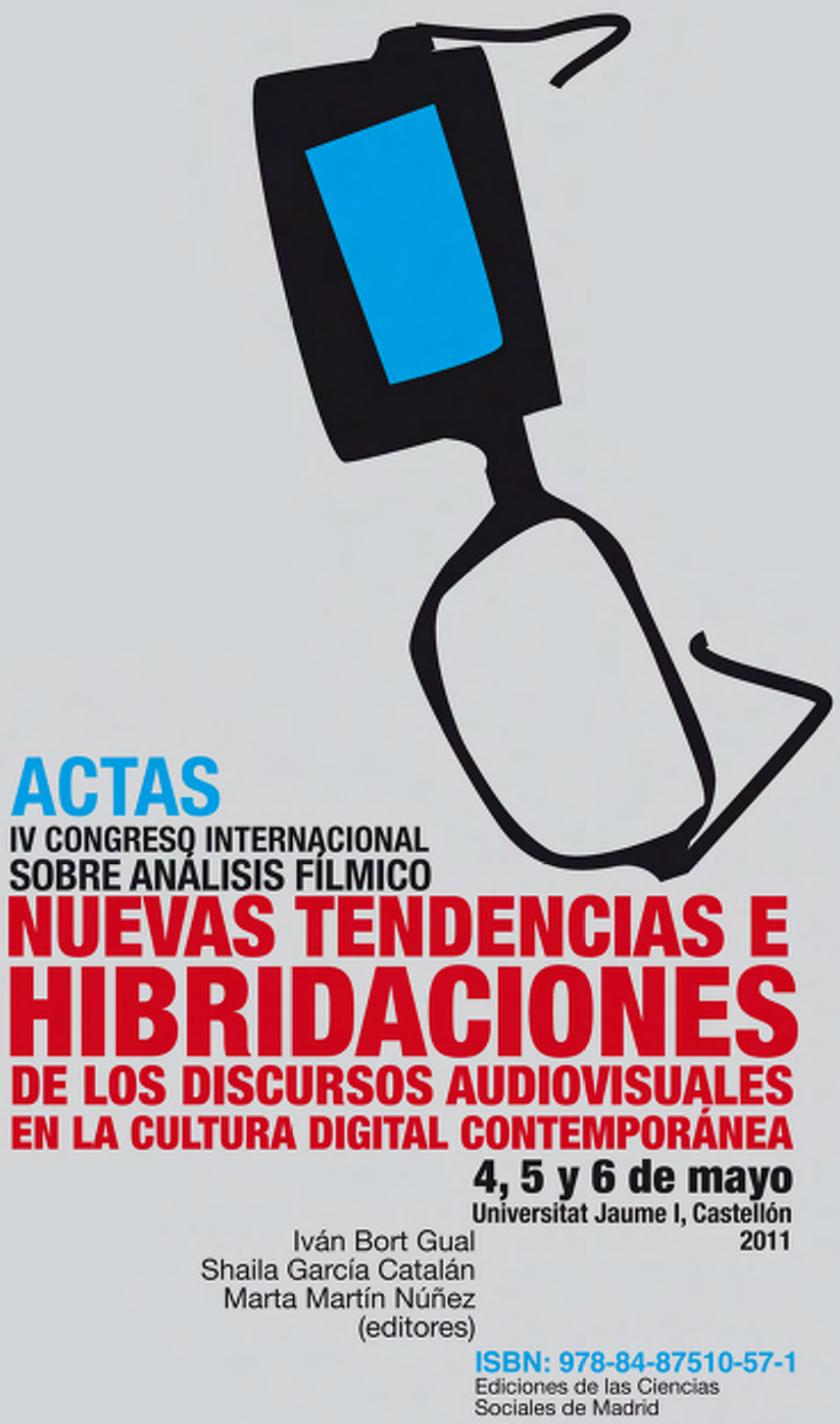




\section{Elementos de seducción} audiovisual en la

$$
\text { oferta de los }
$$

informativos de

$$
\text { televisión en }
$$

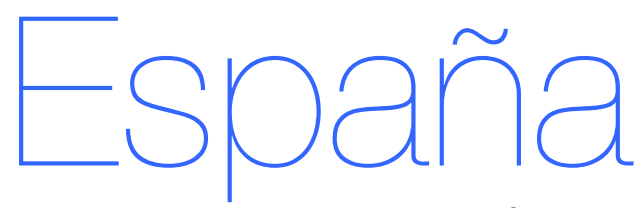

los casos de
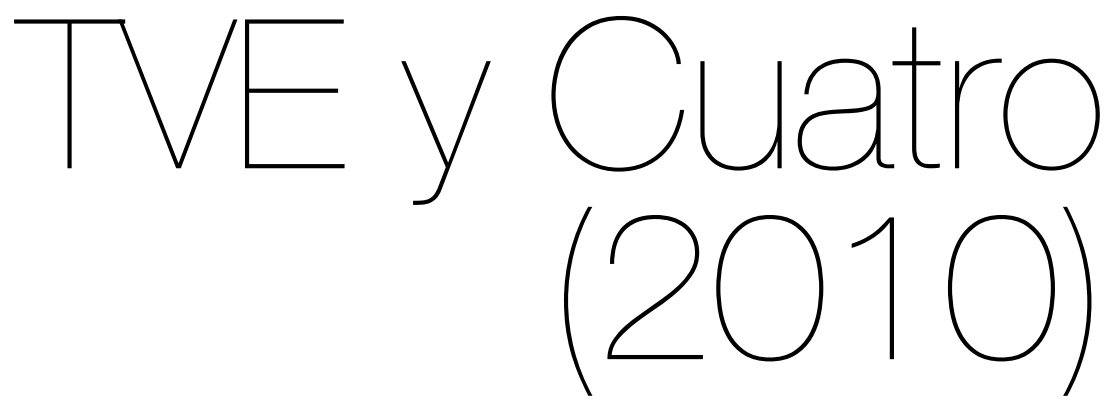

ANA ISABEL SEISDEDOS GARCÍA 
El panorama televisivo actual muestra, cada día con más asiduidad, una clara tendencia hacia la hibridación de contenidos y formatos. Las fronteras de lo real y lo ficticio, lo objetivo y lo intencionado o la información y el entretenimiento se muestran endebles. Esta adulteración de los principios clásicos audiovisuales ha alcanzado a los informativos de televisión, un programa al que se le presupone cierta rigurosidad y objetividad no sólo en sus contenidos sino también en la presentación de los mismos. La preocupación por esta migración de los contenidos audiovisuales arranca en la década de los noventa. Numerosos autores (Altheide, 1976; Bourdieu, 1997; Cebrián Herreros, 1998; García Avilés, 2007; García Jiménez, 1999; González Requena, 1989; López Téllez y Cuenca García, 2005; Marín, 2006; Mateos Pérez, 2009; Oliva y Sitjà, 1996; Ortíz y Pérez Ornia, 2006; Ramonet, 1998; Rodríguez Pastoriza, 2003; Suárez Sián, 2007; Villafante, Bustamante y Prado, 1987) comienzan a reflexionar sobre esta tendencia a entretener en vez de fomentar la comprensión de la realidad en los informativos televisivos. Argumentan que la naturaleza de esta transformación reside, sobre todo, en razones económicas (la competencia entre cadenas deriva en una lucha feroz por captar y mantener la atención del espectador) y técnicas (la necesidad de simplificar y sintetizar cantidades ingentes de información a ritmos vertiginosos debido a las rutinas de producción existentes en el medio audiovisual).

La presente comunicación, enmarcada dentro del concepto infoentretenimiento, surge de un estudio sobre el formato y la estructura de los informativos de TVE1 y Cuatro en la actualidad. Este análisis, realizado a partir de una muestra de una semana de estos informativos en febrero de 2010, pretendía mostrar una radiografía sobre las estructuras de los informativos de estas dos cadenas. Dentro de las conclusiones extraídas se pone de manifiesto la aparición de peligrosos virus como la espectacularización o la ficcionalización de las noticias. Elementos que podemos relacionar de forma inequívoca al concepto de infoentretenimiento. Si bien para muchos autores como Iglesias (1990), Ramonet (1998), Cebrián Herreros (2004), Digón (2005), García Avilés (2007) o Mateos Pérez (2009) esta transformación conlleva una pérdida de profundización y rigor en las informaciones, otros como Suárez Sián (2007), consideran que no tiene por qué asumirse como algo peyorativo. Esta disyuntiva se consolida como una interesante incógnita para disipar en futuras investigaciones a través de estudios experimentales basados en la aplicación de técnicas y herramientas sobre recepción televisiva. Lejos de perspectivas venideras, esta comunicación pretende describir las estrategias y técnicas que se aplican actualmente a las estructuras de los informativos y que se vinculan directamente con la espectacularización y la ficcionalización de la información como consecuencia del infoentretenimiento.

López Téllez y Cuenca García (2005) presentan uno de los decálogos más completos sobre las herramientas y estrategias planteadas para convertir la información en espectáculo. Estos autores hablan de suspense, imágenes impactantes, apelación a los sentimientos o fondos musicales como herramientas claves del montaje espectacular. Además de estas cuestiones, a lo largo de la comunicación completaremos dicha aportación con otros elementos como la alteración de bloques de contenido con la consiguiente tensión en el espectador, la heterogeneidad y dinamismo de los planos empleados a lo largo de todo el informativo o la transformación de los formatos clásicos de las noticias en cuanto a su fisonomía y su duración. 
1. Análisis de los elementos de espectacularización e infoentretenimiento en los informativos de Televisión Española y Cuatro

\subsection{Bloques de contenido heterogéneos: entre la tensión y el aturdimiento del espectador}

Si observamos los informativos de televisión desde una perspectiva global en cuanto a la estructura planteada, el primer asunto que resalta es la organización de los bloques de contenido en su información generalista. La tónica habitual de TVE1 es nacional, economía, internacional, sucesos, sociedad y cultura. Si bien es cierto que los bloques se interrumpen entre ellos en alguna ocasión (por ejemplo, se entremezclan informaciones de nacional y economía), la televisión pública se muestra bastante coherente en el orden de presentación de sus secciones.

Por su parte, Cuatro no presenta una secuencia lógica según los días estudiados. Aunque el arranque y el cierre son medianamente estables (abriendo con nacional y/o economía y cerrando con sociedad y/o cultura por regla general), la estructura de las secciones se presenta variable. Encontramos, por ejemplo, bloques mezclados con noticias de sucesos y sociedad o de internacional y de sucesos.

Esta tendencia a intercalar informaciones de diferentes secciones ya fue señalada en 2005 por López Téllez y Cuenca García en su análisis de los informativos de TVE1, Antena3 y Telecinco. Se refuerza, por tanto, esta conclusión y añadimos los informativos de la cadena Cuatro como clara muestra de esta directriz.

Esta decisión de plantear las secciones de manera heterogénea crea disyuntiva entre los estudiosos del tema. Mientras López Téllez y Cuenca García (2005) no ven con buenos ojos esta opción dado que consideran que puede desorientar al espectador, otros como Sanabri lo consideran como una estrategia: «la importancia o el interés informativo de una noticia puede hacer que se la saque de su bloque lógico para destacarla especialmente [...] logrando una tensión» (1994: 129).

Partiendo de la aportación de Sanabria, es posible interpretar esta estrategia empleada por los informativos de Cuatro como una maniobra para mantener la atención del espectador. Una visión de la escaleta que entronca con la empleada en los guiones de ficción donde se alternan los momentos dramáticos con los minutos de calma. Comparato, en su clasificación de los tipos de guión empleados en cine y televisión, habla de esta estructura como ondulante y señala que «la tensión se mantiene mucho tiempo y puede ocasionar una pérdida de interés» (1989: 90). Como ya se apuntó anteriormente, resultaría interesante analizar las consecuencias del empleo de unas $u$ otras estructuras y su repercusión en la recepción del mensaje informativo audiovisual.

\subsection{Realización dinámica como gancho}

Antes de analizar las estrategias de espectacularización empleadas propiamente en las piezas informativas, observaremos la naturaleza de los planos utilizados en las introducciones que los presentadores hacen a las noticias generalistas desde el plató. TVE1 cuenta con una hegemonía del plano corto fijo (82\%), acompañado por una leve presencia de planos generales en movimiento (16\%) y planos medios en movimiento (2\%). Estos porcentajes responden a la tendencia clásica defendida por Rodríguez Pastoriza, donde aseguraba que «en relación con los planos que fijan la visualización de los conductores de programas, más del 90\% utiliza el primer plano. El resto los muestra en un plano general en el escenario del plató. Con ello asume 
una estética de neutralización a mitad de camino entre la distancia y proximidad, que podría corresponder al deseo de "objetividad"» (2003: 83).

Cuatro, por su parte, emplea una variedad mucho más amplia de planos liderados por los planos medios fijos (52\%) y los generales en movimiento (24\%). En menor medida encontramos planos medios en movimiento, planos generales fijos y cortos fijos $(9 \%, 8 \%$ y $6 \%$ respectivamente) y, anecdóticamente, planos cortos en movimiento (1\%). Cabe reseñar, además, la variedad de planos dentro de una misma categoría, llegando a localizar hasta cuatro tipos de plano medio fijo en el caso del informativo de Cuatro.

Percibimos, por tanto, dos planteamientos enfrentados sobre la planificación visual de los informativos. Mientras TVE1 se muestra más clásico, Cuatro apuesta por una heterogeneidad visual que otorga ritmo al programa. Este tipo de realización caracterizada por su atractivo y su dinamismo se identifica más propiamente en programas de entretenimiento y se aleja del postulado de objetividad planteado anteriormente por Rodríguez Pastoriza. Esta elección apuesta, por tanto, por el espectáculo visual como gancho sensorial para convencer al espectador.

\subsection{Adulteración de las noticias clásicas y creación de nuevos formatos}

Las noticias, columna vertebral de los informativos, también han sucumbido a la búsqueda del espectáculo modificando su esencia clásica en cuanto a su formato y su duración. Partiendo de las aportaciones clásicas realizadas por Cebrián Herreros (1998) y revisadas por otros autores como Bandrés, García Avilés, Pérez y Pérez (2000) o Marín (2006), clasificaríamos los formatos clásicos de noticias en colas, totales, VTR, breves, stand up y directos.

Según las conclusiones obtenidas del estudio, el formato que más se ha reformado son las colas. Las transformaciones se localizan en aspectos como la duración, su peso porcentual en los informativos o su naturaleza propia.

El formato predominante en las noticias generalistas de Televisión Española son los VTR (37\%) seguidos por las colas (24\%), que suelen ir acompañadas por totales (14\%). Los directos (14\%) y las entradillas (10\%) completan la lista de los formatos más empleados de la cadena pública.

Por su parte, Cuatro recurre, en la información generalista, al formato colas con más asiduidad que la cadena pública, coronándose con un 35\% como el más empleado en los informativos. En el caso de los deportes de esta cadena, debemos señalar el reiterativo empleo de este formato (alcanzando más de la mitad de las noticias - 55\%-). Esta hegemonía de las colas, un formato flexible que permite una mayor libertad de comentarios, pretende fomentar el diálogo y el análisis entre los dos presentadores. Este hecho supone una clara hibridación de formatos dado que se promueve una particularidad interpretativa poco afín a los informativos de televisión, donde históricamente se presuponía una presentación y narración más objetiva de los hechos.

En relación a la duración de las colas, en la información generalista de ambas cadenas el formato no alcanza los 30 segundos de duración (20 en el caso de Cuatro y 26 en TVE1). Una extensión que algunos autores, como Cebrián Herreros (1992), consideran mínima para que el destinatario del mensaje pueda decodificarlo adecuadamente y retener los datos esenciales de las noticias. Una característica que entronca con las planteadas sobre el infoentretenimiento: la espectacularización frente a la profundización y rigor de las informaciones. 
La transformación de la naturaleza de las colas se percibe en la cadena Cuatro, que modifica la definición tradicional de este formato en ciertas ocasiones. Plantean lo que podríamos definir como colas en directo, dado que en vez de recurrir al off tradicional, llevan a cabo una retransmisión en directo. Esta estrategia se realizó en dos ocasiones a lo largo de la semana analizada: con la gala en la que se deciden los nominados a los Óscars (2 de febrero) y con el desayuno al que asistió Zapatero con Obama en Estados Unidos (4 de febrero). Otro asunto reseñable es el empleo de colas y de VTR sin off los días 3 y 4 de febrero. Con esta fórmula se pretende apelar a la fuerza de la imagen por sí misma, a su capacidad de contar sin la necesidad de un narrador.

Otro formato fugaz son los breves, que tampoco alcanzan el límite mínimo de 30 segundos de duración (citado anteriormente). Este formato sólo se emplea en Cuatro y que se mueve en torno a los 16 segundos de duración. Esta extensión pone en entredicho las aportaciones históricas que hablaban de una duración entre 20 y 30 segundos (Cebrián Herreros, 1998; Bandrés, García Avilés, Pérez y Pérez, 2000). A pesar de su fugaz duración, los breves pueden coronarse como elementos estructurales tal y como apuntan Bandrés, García Avilés, Pérez y Pérez que los consideran como una «fórmula para romper el ritmo del informativo y avivar el interés de la audiencia» (2000: 115). Con este formato, nos encontramos nuevamente ante técnicas destinadas a agilizar el ritmo y dinamizar las escaletas de los informativos.

Otro de los formatos con claros tintes de renovación son los directos. El empleo de este recurso pretende otorgar, según diferentes autores (Torán, 1982; Cebrián Herreros, 1998; Rodríguez Pastoriza, 2003) calidad a la noticia en términos de objetividad y veracidad. Sin embargo, el creciente incremento de las conexiones con reporteros y emisoras ha derivado en la sospecha, para Ortiz y Pérez Ornia, de que se emplea este recurso "como contribución al espectáculo informativo, aunque no siempre esas conexiones sean sinónimo de información» (2006: 10). Este recelo se ve reforzado por Cebrián Herreros que pasa de considerar los directos como "la información televisiva en su grado máximo" (1998: 489) a criticar que el «directo sólo ofrece la apariencia de los hechos y oculta el trasfondo, la causalidad, las consecuencias. Para lograr esto es preciso el análisis y la reflexión en un tiempo adecuado y distanciado» (2004: 27).

Resulta relevante, por tanto, analizar el empleo de los directos y de la presencia de periodistas dentro de las noticias. Aunque no podemos hablar fielmente de directo, en este apartado incluiremos las entradillas, dado que, al igual que en los directos, se refuerza el valor de la noticia con la presencia del reportero en el lugar de los hechos. Así, sumando directos y entradillas, TVE1 se distancia de Cuatro claramente (24\% frente a un $15 \%$ respectivamente). Aunque no se ha estudiado en profundidad la naturaleza de las noticias que incluyen directos para valorar si estos atienden a la rigurosidad o al espectáculo informativo, sí podemos decir que, en el caso de TVE1, el $24 \%$ sí es un alto porcentaje. Este dato implica que, aproximadamente una de cada cuatro noticias, por su naturaleza informativa, demanda un directo. Hecho que nos hace reflexionar sobre el posible uso banal e innecesario de algunas conexiones con el lugar de los hechos.

Entre una y otra cadena también existen diferencias en relación al peso del reportero y duración. TVE1 confiere una leve pero mayor importancia que Cuatro al reportero (en función del tamaño de la ventana adjudicada) y alcanza casi el minuto 
de duración mientras que en Cuatro ronda los 48 segundos. En ambas cadenas, los directos superan con creces la duración establecida por Oliva y Sitjà (1996) que la situaban entre los 10 y los 20 segundos de extensión (a no ser que se tratara de noticias que exigían mayor nivel de reflexión y análisis o aquellas que no contaban con imágenes que emitir) quedando duplicada en la actualidad.

Más allá de los cambios observados en los formatos clásicos, se ha detectado la presencia de nuevos formatos en los deportes de la cadena Cuatro. Por ejemplo, el 3 de febrero se muestra la sección "cara a cara" consistente en un enfrentamiento dialéctico entre dos personajes que comparten un mismo plano dividido en dos ventanas. Se trata de una novedosa utilización de los totales clásicos para conseguir una polémica. Un gancho que, sin embargo, puede desembocar en la espectacularización de la propia información.

\subsection{Hacia la fugacidad del plano informativo}

Dando un paso más en el análisis buceamos dentro de las propias noticias para analizar la planificación visual empleada. Partiendo de las aportaciones clásicas, Cebrián Herreros (1998) situaba la duración adecuada entre los cuatro y los cinco segundos. En un estudio del año 2000, Bandrés, García Avilés, Pérez y Pérez, comprueban el descenso de este baremo mínimo en un segundo de duración. La presente comunicación se mueve dentro de este nuevo dato dado que la duración de los planos en las noticias con formato de colas es análogo en ambas cadenas y gira en torno a los 3 segundos y medio de duración. Por su parte, en el caso de los VTR, mientras Cuatro mantiene una duración similar a la empleada en las colas, TVE otorga más tiempo a los planos que conforman los VTR, rondando los cuatro segundos. Aunque hemos de presuponer que un segundo de duración no puede ser interpretado como una pérdida en la rigurosidad del plano informativo, sí es cierto que esta tendencia pone de manifiesto la evolución hacia la espectacularización de la que venimos hablando a lo largo de esta comunicación.

Cabe destacar, en este sentido, la presencia de varias noticias en ambas cadenas, relacionadas generalmente con el bloque de cultura, donde se presentan planos frenéticamente cortos. Una directriz que imita la estética del videoclip. Las noticias con este formato suelen estar relacionadas con los estrenos cinematográficos o espectáculos similares. Así, por ejemplo, se emiten los tráiler de las películas sin modificaciones y con una velocidad de planos poco habitual en los informativos convencionales. Encontramos un VTR de TVE1 del 5 de febrero de 2.31 minutos elaborado con 111 planos (lo que supone una media de duración de planos de poco más de un segundo) o, el mismo día en la cadena Cuatro, un vídeo de 92 planos con una duración de 2.05 minutos.

Además de los planos, cabe señalar brevemente, la presencia de declaraciones en las noticias audiovisuales. En los VTR de Televisión Española, localizamos una media de dos totales mientras que en Cuatro roza los tres por vídeo. Aunque el promedio no parezca descabellado, no podemos olvidar que se trata de una media y que encontramos vídeos sin declaraciones directas y, en más de una ocasión, VTR que rondan los 10 totales en el caso de la televisión privada. López Téllez y Cuenca García señalaban ya, en un estudio de 2005, la tendencia en alza de las noticias centradas en las citas y advertían de los peligros de la descontextualización de las frases con la consiguiente pérdida de su sentido original. Este recurso, empleado abusivamente en Cuatro, se concibe como un aliño de calidad cuando 
se trata de declaraciones de autoridad, es decir, emitidas por personajes relevantes, testigos directos de hechos o expertos en los asuntos tratados. Sin embargo, en la actualidad redundan más los totales de la vox populi que no llegan a concebirse como suplementos de rigurosidad. Así, no se espectaculariza desde el sentido más estricto del concepto, pero se banaliza y se cae en el sensacionalismo.

\subsection{Música: de lo espectacular a lo ficticio}

Existen diferencias relevantes en el uso que TVE1 y Cuatro hacen de la música tanto en la información general como en la deportiva. Si bien es cierto que los porcentajes de noticias generalistas acompañadas por melodías son similares en ambas televisiones (3\% y 4\%), la naturaleza de la música es diferente. La presencia musical en la cadena privada se centra en una sintonía que acompaña a un bloque de unas 3 ó 4 noticias breves que giran en torno a los 50 segundos de duración total. Se trataría, por tanto, de un elemento dinamizador que otorga cierto ritmo a estas informaciones escuetas y cuyo fin podría considerarse funcional, al igual que en cabeceras, titulares, sumarios o transiciones. Sin embargo, para García Jiménez la presentación de «las noticias (al menos las del sumario) con un fondo musical continuo [...] adultera la desnudez exigible de los hechos noticiables» (1999: 63). Un efecto que podría interpretarse, según López Tellez y Cuenca García (2005), como un elemento de espectacularización que desvirtuaría la naturaleza de la información. Así, estudiosos como Hills remarcan que «el único sonido que puede corresponder a la imagen es el ambiental» (1991: 142).

Diferente es el sentido de la música en las informaciones generalistas de TVE1. En este caso, aunque la presencia melódica podría considerarse anecdótica ya que se emplea, de media, en una sola noticia por informativo (lo que supone un 3\% del total), la función que ésta adquiere cuenta con connotaciones estilísticas.

La música, en general, puede interferir en la objetividad de la noticia, por lo tanto, suele desecharse de las noticias de un telediario. Sólo quedan algunas noticias en las que aparece de fondo como ocurre con la información meteorológica, la deportiva y taurina (Cebrián Herreros, 1998: 489).

A este listado cabe añadir las noticias de cultura, que son las que, en el caso de la televisión pública, se presentan acompañadas de un fondo musical.

Deportes

Cuatro

comparó a los jugadores del Atlético de Madrid con los enanitos de Blancanieves
El panorama de porcentajes cambia radicalmente cuando nos centramos en la presencia de música en las informaciones deportivas de Cuatro. El índice de noticias acompañadas por un fondo musical se dispara para situarse en un $42 \%$, lo que supone un promedio ligeramente superior a 8 noticias deportivas con música por informativo. Y no sólo cabe destacar este dato cuantitativo, sino analizar, al igual que en el caso de la información generalista, el sentido de la música en las piezas. En el caso de Cuatro las canciones adquieren una connotación más relacionada con el entretenimiento y la ficción que con el mero acompañamiento musical. Así, 
localizamos, a modo de ejemplo, una noticia que compara a los jugadores del Atlético de Madrid con los enanitos de Blancanieves y en la que se emplean imágenes y la melodía del filme para ilustrar la información.

Se trata de una técnica que puede ser interpretada como una verdadera destreza de la ficción y no de la información. Las músicas que acompañan las informaciones deportivas de la cadena Cuatro, no pueden calificarse, por tanto, como meros fondos musicales que acompañan o dinamizan, sino como verdaderos protagonistas de las informaciones.

\subsection{El suspense en el relato informativo}

El vínculo más directo de la información con la ficción se pone de manifiesto en la sección de deportes de Cuatro con el empleo de un suspense manifiesto. Para mantener la atención del espectador se muestra una incógnita en el arranque del informativo deportivo (se muestran imágenes y se plantea un enigma como ¿quién será el niño de la fotografía? o ¿cómo terminará esta jugada?) que no se desvelará hasta la conclusión del mismo. Se trata de una apelación directa al espectador que ya señalaba González Requena como «la formulación de una expectativa sobre la emergencia de un acontecimiento nuclear y la puesta en suspenso o dilación de su resolución» (1989: 31).

\subsection{Los rótulos de entretenimiento en Cuatro como información distendida}

El último elemento destacable para este análisis es el empleo de lo que hemos denominado como "rótulos de entretenimiento" que alude a la sobreimpresión en pantalla de frases de carácter anecdótico, ocioso o de entretenimiento.

La presencia de rótulos informativos (entendidos como una sobreimpresión en pantalla encargada de ofrecer datos sobre la noticia que se está relatando) es, en ambas cadenas, casi inexistente (3,4 de media en TVE1 y 2,4 en Cuatro). Este hecho pone de manifiesto la exigua preocupación por un elemento que, a priori, favorece la recepción y comprensión del mensaje gracias a su intencionalidad de síntesis de las informaciones. Sin embargo, los rótulos de entretenimiento se muestran imperiosos en la cadena privada con su presencia en casi 1 de cada 3 noticias deportivas. Este hecho le otorga un claro sentido de infoentretenimiento a las noticias deportivas de Cuatro que, más que informaciones puras se convierten en relatos distendidos y anecdóticos.

Llama la atención, así, la comparación entre el peso de los rótulos informativos y de entretenimiento en los informativos de la televisión privada. Los primeros, a los que se les supone cierta rigurosidad y que abogan por la comprensión del mensaje audiovisual se encuentran relegados para otorgarle protagonismo a la creatividad y a la distracción del relato informativo de los deportes.

2. Conclusiones: la espectacularización como clave del infoentretenimiento en los informativos de televisión

García Jiménez plantea cuatro tipos de estructuras de los telediarios: códica o medial, informativa, narrativa y dramática, y persuasiva. Sin bien es cierto que ambos modelos de informativos (TVE1 y Cuatro) presentan características de los cuatro modelos planteados por García Jiménez, teniendo en cuenta la naturaleza de esta comunicación, debemos centrarnos en la narrativa y dramática. Para 
García Jiménez, la estructura narrativa «regula la secuencialidad del relato informativo» (1999: 63) y la dramática alude a la vertebración del programa en planteamiento, desarrollo y desenlace. Para este autor, la combinación de ambas estructuras «aproxima el relato informativo al relato de ficción» (1999: 63). Esta hibridación hacia la ficción, convierte la información en entretenimiento y espectáculo a través de recursos como la alteración de secuencias, la presentación de noticias con un fondo musical o el suspense.

Así, partiendo de esta aportación y resumiendo a grandes rasgos, podemos hablar de dos modelos de informativos claramente diferenciados. TVE1 se presenta como un informativo formal y rígido en términos estructurales cumpliendo, así, con el papel de telediario sobrio que se le presupone a la cadena pública. Sus informaciones no dan demasiada cabida a elementos innovadores relacionados con el infoentretenimiento, aunque sí se localizan pequeñas pinceladas de espectacularización en algunas de sus piezas informativas. En el lado opuesto, la cadena Cuatro, se caracteriza por la innovación y la ruptura en sus escaletas. La pauta de sus informativos se guía por un ritmo ágil en la narración y por la incorporación de elementos de ficción y espectáculo en sus piezas informativas.

TVE1 recurre al espectáculo informativo a través de recursos blandos y enmascarados. Por un lado, podemos señalar que el empleo de fondos musicales en las noticias de cultura podría encubrirse como un mero recurso estético, teniendo en cuenta la naturaleza de este tipo de informaciones. Por otra parte, otro aspecto reseñable es la utilización de directos en un alto porcentaje (casi un 25\% de las noticias cuentan con uno). Siempre y cuando se demostrara que el superfluo uso de este recurso alude a razones de rigurosidad informativa y no de aprovechamiento banal como muestra de su potencial estructural como cadena pública, podríamos obviar este dato y no relacionarlo directamente con la espectacularización de la información.

Si hemos caracterizado como blandos y enmascarados los recursos técnicos y estructurales de Televisión Española, por comparación directa podríamos hablar de estrategias duras y manifiestas en Cuatro. Encontramos recursos que fomentan el espectáculo visual, estructural y dialéctico.

El espectáculo visual se pone de manifiesto a través de la planificación con una realización heterogénea que entremezcla planos de diversa naturaleza y se consolida como claro gancho sensorial para el espectador. En este apartado podríamos incluir el empleo de los rótulos de entretenimiento y guiños de ficción en la sección de deportes. A través de este recurso se pone de manifiesto la pretensión de narrar las informaciones

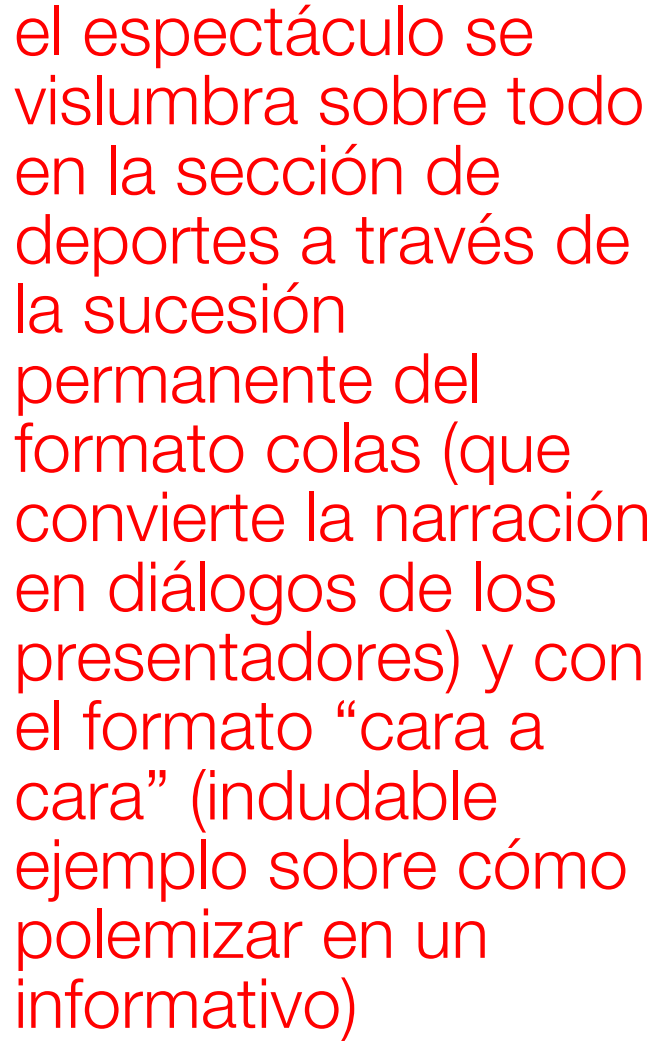
el espectáculo se vislumbra sobre todo en la sección de deportes a través de la sucesion permanente de formato colas (que convierte la narración en diálogos de los presentadores) y con el formato "cara a cara" (indudable ejemplo sobre cómo polemizar en un informativo) 
de manera coloquial y entretenida con claros toques de humor.

Cuando hablamos de espectáculo estructural nos referimos a la búsqueda del ritmo frenético a través de planos de corta duración, noticias escuetas (recordemos que las colas se consolidan como formato predominante de Cuatro), planteamientos dramáticos con picos de tensión (como consecuencia de la alteración de sus bloques de contenido), la música como elemento dinamizador o el empleo de un suspense notorio. Todos estos elementos convierten las escaletas de estos informativos en estructuras cardiacas.

El espectáculo dialéctico se vislumbra notoriamente en la sección de deportes a través de la sucesión permanente del formato colas (que permite convertir la narración de las noticias en diálogos distendidos de los presentadores) y con el formato "cara a cara" (indudable ejemplo sobre cómo polemizar en un informativo). Además, las colas en directo o sin off en la información generalista o el abusivo empleo de totales, aluden también a este espectáculo dialéctico, aunque de manera más sutil.

Para futuros desarrollos queda pendiente la comprobación de la eficacia informativa de recepción y comprensión televisiva de todos estos recursos. Los antecedentes teóricos revisados consideran que la mayoría de las estrategias de espectáculo y entretenimiento en las informaciones empobrecen la naturaleza rigurosa y objetiva de las informaciones. Sin embargo, vista la imparable evolución que están teniendo los informativos en televisión, cabe replantearse si deberían asumirse los cambios desde la visión laudatoria del concepto innovación o, por el contrario, los productores de los telediarios deberían echar la vista atrás para amoldarse a las estructuras clásicas.

\section{BIBLIOGRAFÍA}

ALTHEIDE, D.L. (1976) Creating Reality: How Tv News Distorts Events. London: Sage.

BANDRÉS, E., GARCÍA AVILÉS, J. A., PÉREZ, G. y PÉREZ, J. (2000) El periodismo en la era digital. Barcelona: Paidós.

BOURDIEU, P. (1997) Sobre la televisión. Barcelona: Editorial Anagrama.

CEBRIÁN HERREROS, M. (1992) Géneros informativos audiovisuales. Madrid: Editorial Ciencia.

CEBRIÁN HERREROS, M. (1998) Información televisiva. Mediaciones, Contenidos, Expresión y Programación. Madrid: Editorial Síntesis.

CEBRIÁN HERREROS, M. (2004) La información en televisión. Obsesión mercantil y política. Barcelona: Gedisa.

COMPARATO, D. (1989) El guió. Barcelona: Publicaciones UAB.

DIGÓN, P. (2005). "Las otras noticias y los telediarios españoles: una propuesta de análisis". En Revista Comunicar, № 25. Octubre.

[http://www.revistacomunicar.com/index.php?contenido=detalles\&numero=25\&arti culo=25-2005-141, consultado el 22/11/2010]

GARCÍA AVILÉS, J.A. (2007) "El infoentretenimiento en los informativos de la U.E". Anàlisi, 35, pp. 47-63.

GARCÍA JIMÉNEZ, J. (1999) Información audiovisual: los géneros. Madrid: Paraninfo. 
GONZÁLEZ REQUENA, J. (1989) Espectáculo informativo o la amenaza de lo real. Madrid: Akal.

HILLS, G. (1991) Los informativos en televisión. Madrid: IORTV.

IGLESIAS, F. (1990) La televisión dominada. Madrid: Rialp.

LÓPEZ TÉLLEZ, A. y CUENCA GARCÍA, F.A. (2005) "Televisión e información:

análisis de los criterios de calidad en los informativos de las cadenas nacionales".

En Revista Comunicar, № 25.

[http://dialnet.unirioja.es/servlet/articulo?codigo=2927462, consultado el 14/12/2010]

MARÍN, C. (2006) Periodismo Audiovisual. Información, entretenimiento y tecnologías multimedia. Barcelona: Gedisa.

MATEOS PÉREZ, J. (2009) La información como espectáculo en el nacimiento de la televisión privada española (1990-1994). Estudios sobre el mensaje periodístico, No 15.

[http://revistas.ucm.es/inf/11341629/articulos/ESMP0909110315A.PDF, consultado el 17/07/2010]

OLIVA, LI. y SITJÀ, X. (1996) Las noticias en televisión. Madrid: IORTV.

ORTÍZ, M.A. y PÉREZ ORNIA (2006) Claves para elaborar la información en radio y televisión. Madrid: IORTV.

RAMONET, I. (1998) La tiranía de la comunicación. Madrid: Debate.

RODRÍGUEZ PASTORIZA, F. (2003) La mirada en el cristal. La información en televisión. Madrid: Fragua.

SANABRIA, F. (1994) Información audiovisual. Teoría y técnica de la información radiofónica y televisiva. Barcelona: Bosch Casa Editorial.

SUÁREZ SIAN, M. (2007) Dramaturgia audiovisual. Guión y estructuras de informativos en radio y televisión. Sevilla: Comunicación Social.

TORÁN, L.E. (1982) La información en televisión. Barcelona: Mitre.

VILLAFANTE, J., BUSTAMANTE, E. y PRADO. E. (1987) Fabricar noticias. Las rutinas productivas en radio y televisión. Barcelona: Mitre. 